\title{
POEM: Five Years of Experience in a Single East European Center
}

\author{
Cristian Tefas $^{1,2}$, Carina Boroș ${ }^{1}$, Lidia Ciobanu ${ }^{1,2}$, Teodora Surdea-Blaga ${ }^{2,3}$, Alina Tanțău ${ }^{2,4}$, Marcel Tanțău ${ }^{1,2}$
}

1) Gastroenterology

Department, Institute of

Gastroenterology and

Hepatology, Cluj-Napoca;

2) Iuliu Hațieganu University

of Medicine and Pharmacy,

Cluj-Napoca;

3) $2^{\text {nd }}$ Medical Clinic, Cluj-

Napoca;

4) $4^{\text {th }}$ Medical Clinic, Cluj-

Napoca, Romania

\begin{abstract}
Background \& Aims: Achalasia is an esophageal motility disorder with many available therapies. Peroral endoscopic myotomy (POEM) is a therapeutic alternative to surgical myotomy, harboring significant potential short term advantages. Our aim was to analyze a single-series POEM's learning curve, safety and efficiency over short, medium and long-terms in an East European Center.

Methods: This observational, prospective study was carried out in the Regional Institute of Gastroenterology and Hepatology, Cluj-Napoca, Romania. Patients with symptomatic achalasia (Eckardt score $>3$ ) and pre-op evaluations consistent with the diagnosis of achalasia were included. All POEMs were performed by a highly skilled endoscopist. All patients were allowed to eat 48 hours after POEM. An esophagography was performed in all patients to exclude any leakage. The patients were asked to return for follow-up at established intervals: 1 month, 6 months, 12 months, and annually thereafter.

Results: 136 patients were included with an average duration of symptomatology of 36.75 months. The procedure was technically successful in all patients, while a clinical success rate was achieved in $87.5 \%(n=119)$ of patients after one POEM session. The success rate was $92.64 \%$ after 6 months, $91.17 \%$ after one year, $88.9 \%$ after 2 years, and $87.5 \%$ after 3 years or more; $12.5 \%$ of patients required additional treatment. Eighteen patients (13.23\%) presented major early complications. Gastroesophageal reflux disease was encountered in 16 patients immediately after POEM and in 22 patients at subsequent follow-ups.

Conclusion: POEM is a safe and effective minimally invasive therapeutic option which can substitute surgical myotomy, having a high success rate and a low rate of adverse events in short, medium and long-term.
\end{abstract}

Key words: achalasia - peroral endoscopic myotomy - eastern Europe - learning curve.

Abbreviations: GERD: gastroesophageal reflux disease; GERD-HRQL: GERD-health related quality of life questionnaire; LES: lower esophageal sphincter; POEM: peroral endoscopic myotomy; PPI: proton-pump inhibitor.

\section{INTRODUCTION}

Achalasia is an idiopathic, relatively rare disease, characterized by incomplete relaxation of the lower esophageal sphincter (LES) during swallowing and loss of peristalsis in the distal esophagus or uncoordinated contractions in the rest of the esophagus [1-3]. Therapeutic options include pharmacological agents, endoscopic treatment and surgery, the endpoint being the forced relaxation of the LES and faster esophageal emptying $[1,4]$.
Peroral endoscopic myotomy (POEM) is considered one of the go-to therapeutic procedures in achalasia, being faster, cheaper and as efficient as its surgical counterpart [5]. However, it is used in only a few centers around the world given that it is reserved for highly experienced endoscopists. Hungness et al. [6] and others [7-9] noticed that the learning curve for POEM reached a plateau after 15-20 interventions, with the outcome being based on efficacy.

Although there are many centers that use POEM in Central and Western Europe, this technique is rare in Eastern Europe $[11,17]$, our center being the first and only one in Romania. We performed the first POEM in November 2013 [11] and reported the learning curve in 2015 [12].

We currently present the Romanian experience with POEM in a prospective study. Our main aims were to analyze the efficacy of the technique as well as its possible complications. Our secondary aims were to evaluate the clinical, radiological, 
endoscopic and manometric improvement in patients at 1,6 and 12 months after treatment, and annually afterwards.

\section{METHODS}

Consecutive patients with symptomatic achalasia admitted between November 2013 and February 2019 were included. Demographic data, symptom duration, previous treatment, length of hospital stay, procedural time, length of myotomy, preoperative and postoperative Eckardt scores and LES pressures were collected and analyzed. The type of achalasia was classified using the Chicago classification [1].

To quantify the clinical status and its improvement we used the Eckardt score, defined as the sum of dysphagia, regurgitation, chest pain and weight loss scores, each being assigned a value from 0 to 3 depending on its severity.

All patients underwent POEM at the Regional Institute of Gastroenterology and Hepatology, Cluj-Napoca, Romania. Patients with symptomatic achalasia, defined as an Eckardt score of 4 and pre-op barium swallow, manometry and upper gastrointestinal (GI) endoscopy consistent with the diagnosis of achalasia were included. Exclusion criteria included premalignant or malignant esophageal lesions, patients with previous esophageal or gastric surgery, and those with esophageal varices or coagulopathy.

All included patients provided written informed consent after receiving detailed verbal and written explanations of the procedure. In the case of patients under 18 years, consent was obtained from their parents.

Preoperative preparation consisted of a liquid diet for 48 hours. For 24 hours before the procedure, the patient was placed on nil per os and a naso-esophageal tube was inserted in order to suction possible esophageal residue.

The same highly experienced gastroenterologist (M.T.) performed all POEMs. All patients were placed under general anesthesia. CO2 was used for insufflation, and a high-definition gastroscope was inserted. After cutting the mucosal layer using a triangle-tipped knife (Olympus Co, Japan), a submucosal tunnel was created approximately $12 \mathrm{~cm}$ proximally to the esogastric junction and $3 \mathrm{~cm}$ into the stomach. Afterwards, myotomy of the circular muscular layer was executed starting at the level of the mucosal incision. For most patients, the myotomy was made on the anterior esophageal wall, between 11 and 2 o'clock. If the patient had underwent previous treatment and significant fibrosis was seen at endoscopy, the myotomy was performed on the posterior wall, at 7 oclock. Lastly, the mucosal breach was closed using endoscopic clips.

All patients were kept nil per os for 24 hours after POEM. Intravenous antibiotics (Clindamycin $600 \mathrm{mg} /$ day and Ceftriaxone $2 \mathrm{~g} /$ day) and proton-pump inhibitors (PPIs) (80 $\mathrm{mg} /$ day) were administered one hour before the procedure and continued for a minimum of 3 days after the procedure was completed.

On the first postoperative day, patients underwent a contrast swallow (Iopamiro 300, Bracco) to rule out a possible transmural perforation. If a perforation was excluded, patients were placed on a liquid diet for 24 hours with subsequent resumption of food intake. Patients were then discharged, placed on a soft diet for 14 days and instructed to use a daily double dose of PPIs for 4 weeks.

All patients were asked to return for follow-up at established intervals: 1 month, 6 months, 12 months, and annually thereafter. Reported symptoms specific to reflux disease were assessed according to the Gastroesophageal Reflux Disease Health Related Quality of Life Questionnaire (GERD-HRQL).

Statistical analysis was performed using SPSS v.24 (SPSS Inc, Chicago, Illinois). Categorical variables were compared using a Fisher exact test. Relationships between preoperative and postoperative variables were assessed using a Spearman rank-correlation coefficient. Statistical significance was based on 2-sided, design-based tests evaluated at a p-value of 0.05 .

\section{RESULTS}

One hundred thirty-six patients were included, with a mean age of 48 years; $48.52 \%(n=66)$ being male. The average duration of symptomatology was 36.75 months. One hundred three patients $(75.73 \%)$ had symptoms for at least one year before the endoscopic intervention and 19 (13.97\%) patients presented symptoms for at least 5 years (Table I).

Table I. Demographic data, clinical and manometric values before and after the procedure

\begin{tabular}{|c|c|c|}
\hline Parameter & Mean & $\mathrm{p}$ \\
\hline Male gender, $\mathrm{n}(\%)$ & $66(48.52 \%)$ & \\
\hline Mean age (years) & $48 \pm 15.68$ (range 4-87) & \\
\hline $\begin{array}{l}\text { Mean symptoms duration } \\
\text { (months) }\end{array}$ & $\begin{array}{l}36.75 \pm 49.38 \\
\text { (range } 1-336 \text { ) }\end{array}$ & \\
\hline \multicolumn{3}{|l|}{ Type of achalasia, n (\%) } \\
\hline Type I & $71(52.2 \%)$ & \\
\hline Type II & $42(30.88 \%)$ & N/A \\
\hline Type III & $12(8.82 \%)$ & \\
\hline Unspecified & $10(7.35 \%)$ & \\
\hline \multicolumn{3}{|l|}{ Previous treatment $\mathrm{n}(\%)$} \\
\hline Pneumatic dilatation & $23(16.92 \%)$ & \\
\hline Botulinum toxin & $1(0.72 \%)$ & \\
\hline Heller myotomy & $9(6.61 \%)$ & \\
\hline \multicolumn{3}{|l|}{ Mean LES pressure (mmHg) } \\
\hline Before & $45.51 \pm 17.48($ range $20-90)$ & \\
\hline After & $11.22 \pm 9.41($ range $0-45)$ & $<0.001$ \\
\hline \multicolumn{3}{|l|}{ Mean POEM Eckardt score } \\
\hline Before & $7.72 \pm 1.79($ range $4-12)$ & \\
\hline After & $0.85 \pm 1.33($ range $0-8)$ & $<0.001$ \\
\hline \multicolumn{3}{|l|}{ Mean CRP values (mg/L) } \\
\hline Before & $0.74 \pm 1.29($ range $0.28-6.79)$ & $<0.001$ \\
\hline After & $4.66 \pm 3.83($ range $0.29-17.11)$ & \\
\hline \multicolumn{3}{|l|}{ Mean WBC count (cells $/ \mu \mathrm{L})$} \\
\hline Before & $\begin{array}{l}6990.53 \pm 1931.91 \\
\text { (range 6660-13930) }\end{array}$ & \\
\hline After & $\begin{array}{l}11840.23 \pm 4368.65 \\
\text { (range 5083-30410) }\end{array}$ & $<0.001$ \\
\hline
\end{tabular}

LES: lower esophageal sphincter; CRP: C reactive protein; WBC: white blood count 
Based on high-resolution manometry, type I achalasia was present in 71 patients (52.2\%), type II in 42 patients (30.88\%) and type III in 12 patients $(8.82 \%)$. The remaining patients had an unspecified type of achalasia, as manometry was inconclusive. Thirty-three patients $(24.26 \%)$ had underwent previous therapy (Table I).

In 131 (96.32\%) cases, myotomy was performed on the anterior esophageal wall, while in 5 patients $(3.67 \%)$ the posterior wall was chosen. Mean procedural time was $65 \pm 28.76$ minutes. The mean myotomy length was $15.5 \pm 4.19$ centimeters and the mean number of clips used to close the mucosal breach was $7 \pm 5.57$ (Table II). The procedure was technically successful in all patients.

Table II. Procedural data and outcome in our patients

\begin{tabular}{ll}
\hline Mean operative time (minutes) & $65 \pm 28.76$ (range 35-180) \\
Mean myotomy length (cm) & $15.5 \pm 4.19$ (range 5-18) \\
Mean number of clips & $7 \pm 5.57$ (range 3-24) \\
Orientation of myotomy, n (\%) & $131(96.32 \%)$ \\
$\quad$ Anterior & $5(3.67 \%)$ \\
$\quad$ Posterior & $4.08 \pm 2.26$ (range 1-14) \\
Mean hospital stay (days) & \\
Early minor adverse events, $\mathrm{n}(\%)$ & $13(9.56 \%)$ \\
Subcutaneous emphysema & $1(0.73 \%)$ \\
Pneumothorax & $50(36.76 \%)$ \\
Pneumoperitoneum & \\
Early major adverse events, $\mathrm{n}(\%)$ & $3(2.2 \%)$ \\
Bleeding & $9(6.61 \%)$ \\
Esophageal leakages & $3(2.2 \%)$ \\
Gastric leakages & $5(3.67 \%)$ \\
Clip dislodgement & $2(1.57 \%)$ \\
Arrhythmias & $18(13.23 \%)$ \\
GERD (\%) & \\
Post-POEM treatment, $\mathrm{n}(\%)$ & \\
\hline
\end{tabular}

Early complications were divided into minor, meaning those associated with insufflation and major, represented by bleeding, perforations, leakages, arrhythmias and clip dislodgement.

Fifty-seven $(41.91 \%)$ patients had insufflation-associated events: $9.56 \%(n=13)$ had subcutaneous emphysema, $0.73 \%(n=1)$ had pneumothorax and $36.76 \%(n=50)$ had pneumoperitoneum, half of them required percutaneous drainage.

Eighteen patients (13.23\%) presented major early complications, all of which were managed endoscopically. These adverse events were represented by: bleeding, esophageal leakage, gastric leakage, clip dislodgement and procedural arrhythmias (Table II). Leakages were closed using endoclips and in one case, a fully covered esophageal stent was used, as the mucosal defect was too large. The stent was kept in place for 10 days and subsequently removed.

Mean hospital stay was 4.08 days (range 1-14). No surgical conversion was required and the mortality rate was 0 .
The learning curve was considered to have a cut-off of 20 cases, as noted in previous reports $[7,8]$. The risk for major complications increased when the procedures were performed during the learning curve $(\mathrm{OR}=4.760, \mathrm{p}<0.05)$. The rates of minor complications were not influenced by the learning curve $(p=0.259)$. However the duration of the intervention shortened as the operator became more proficient $(\mathrm{p}<0.001)$.

Average duration of follow-up was 33.39 months; $88.23 \%$ $(n=120)$ of patients returned for the 1-month follow-up, $73.52 \%$ $(n=100)$ at 6 months, $67.64 \%(n=92)$ at one year, 56.35\% $(n=78)$ at two years and $40.44 \%(n=55)$ at three years or above. Sixteen patients were lost to follow-up.

The mean Eckardt score at one month was 0.85 (95\%CI: 0.62-1.09) and the corresponding pressure was $11.22 \mathrm{mmHg}$ (95\%CI: 9.54-12.92) (Figs. 1 and 2). Clinical success rate, defined as an Eckardt score $\leq 3$, was achieved in 87.5\% (95\%CI: 80.21-94.78\%) of patients after one POEM session.

The main late complication was GERD, $16.17 \%(n=22)$ of patients reporting symptoms of reflux and esophagitis was encountered in 10 patients $(7.35 \%)$ at one month.

Subsequent Eckardt scores and LES pressures are illustrated in Figs. 1 and 2. During follow-up, both mean Eckardt score and LES pressure slightly increased.

The success rate of POEM was 92.64\% (95\%CI: 88.2-96.99) after 6 months, $91.17 \%$ (95\%CI: 86.3-95.88\%) after one year, 88.9\% (95\%CI: 83.62-94.17) after 2 years, and $87.5 \%$ (95\%CI: $80.21-94.78 \%)$ after 3 years or more. The success rate for type I achalasia was $88.73 \%$ (95\%CI: 81.33-96.06\%), 85.71\% (95\%CI: 75.11-96.28\%) for type II and 83.33\% (95\%CI: 62.24- 100\%) for type III. Clinical success was achieved in $88.88 \%$ (95\%CI: $74.37-100 \%$ ) of elderly patients (>65 years old), and 100\% in those less than 18 years of age.

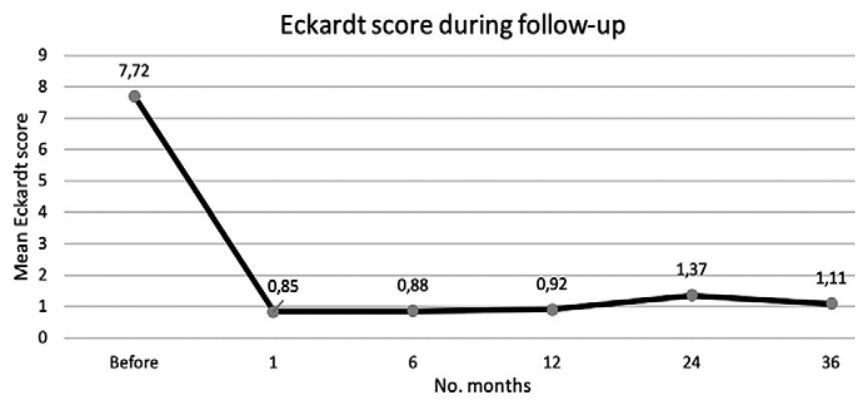

Fig. 1. Average Eckardt scores at baseline and following POEM at one, six, 12, 24 and 36 months.

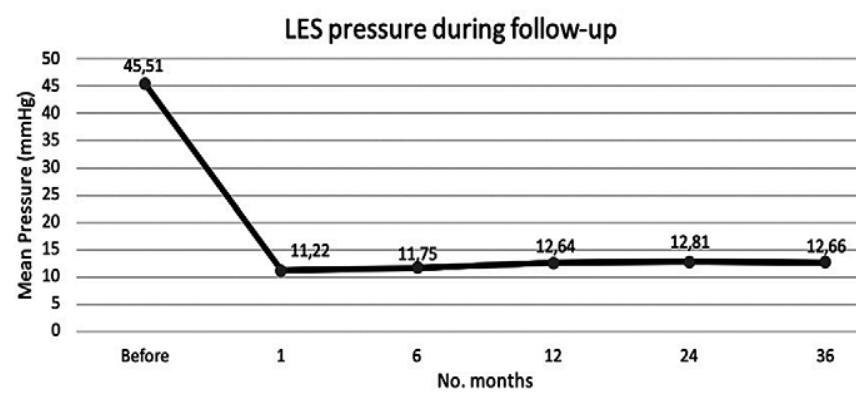

Fig. 2. Average LES pressures at baseline and following POEM at one, six, 12, 24 and 36 months. 
Endoscopic features of reflux esophagitis were observed in $18(13.23 \%)$ of patients at subsequent follow-ups.

Seventeen (12.5\%) patients required additional treatment, as Eckardt scores were $>3$ at various points during follow-up. Sixteen $(11.76 \%)$ patients underwent follow-up pneumatic dilatation, while in one patient another POEM session was required.

\section{DISCUSSION}

Peroral endoscopic myotomy is still developing, having been recently introduced as an alternative treatment of achalasia. Even if this procedure has seen exponential growth, published data is still limited. The International POEM Survey demonstrated that it represents a shift in achalasia therapy, an effective natural orifice transluminal endoscopic surgery approach to LES myotomy [13].

Laparoscopic Heller myotomy was considered the standard surgical procedure for achalasia, with success rates ranging between $88 \%$ and $95 \%$ [14] and favorable long-term results [15]. In a multicenter study which included 75 patients with achalasia and compared the clinical response of POEM $(n=49)$ to laparoscopic Heller myotomy $(n=26)$, the former had better outcomes with more symptom relief and less adverse events [16]. At the same time, other studies concluded that the two procedures are similar regarding clinical success and GERD rates [17-19].

Choosing the correct treatment for the elderly as well as for children is an ongoing debate. In the elderly, on account of associated diseases, endoscopic treatment is used as the first line. The clinical success rate in our study for this subgroup was similar to the overall success rate $[20,21]$.

Regarding children, we performed POEM in 4 patients under 18 years, with the youngest being 4 years old. Over followup, none of the four patients required additional treatment after POEM. The efficiency of POEM for pediatric patients with achalasia seems to be better compared with pneumatic dilatation [21] with Nabi et al. presenting a clinical success of POEM therapy in over $95 \%$ for patients under 18 years old [22].

For patients who underwent surgical treatment, but without clinical improvement, several treatment options have been tried. Surgical re-intervention is not the best choice, due to local adhesions and tissue fibrosis. Posterior surgical myotomy is not technically feasible, with a high risk of secondary failure or complications, such as esophageal perforation [23]. Endoscopic myotomy can be performed on the posterior wall or on the opposite side of the initial incision, with good results regarding symptom regression and no additional adverse events $[5,21$, 24-28], certifying that previous treatment does not necessarily influence the therapeutic failure. These results were confirmed by other studies as well [7, 15, 27, 29].

Full thickness myotomy is the basis for conventional surgical myotomy. However, the muscle layer responsible for achalasia is the circular one, making full thickness myotomy unnecessary [30-32]. In a study that compared the efficacy and safety of full thickness myotomy with selective circular myotomy for 123 patients with severe achalasia, no differences between the two groups were observed in terms of Eckardt score improvement, esophageal diameter or adverse events [31]. Wang et al. [4,
33, 34] described a shorter procedural time for full thickness myotomy versus selective circular myotomy, however the results published by a comparative study demonstrated that GERD is more common in the group with full thickness myotomy [34]. The longitudinal muscle fibers are part of the antireflux mechanisms, which are preserved when performing a selective myotomy, reducing the risk of GERD. All POEMs in our study were performed by selective circular myotomy and the incidence of GERD was $13.23 \%$, versus the rate of $60 \%$ described by Duan et al. [31] by performing full thickness myotomy.

Gastric myotomy favors esophageal reflux, especially in the case of extensive ones [35]. However, to provide an adequate relief of symptoms, a gastric myotomy of $2-3 \mathrm{~cm}$ is required. This has not been associated with a higher incidence of GERD $[36,37]$. In our study, the mean length of gastric myotomy was $2.79 \mathrm{~cm}$, and so patients were not exposed to a higher risk of GERD [37].

When compared to surgical standard treatment, POEM appears to have lower rates of side effects (6\% vs. $27 \%$ ) [16], and mortality $(0.025 \%$ vs. $0.3 \%)$ [30]. Side effects associated with insufflation are frequently asymptomatic and have an incidence between $0 \%$ and $72 \%$ [3]. If symptomatic, pneumoperitoneum or pneumothorax can be drained, whereas subcutaneous emphysema rarely needs to be treated $[3,9,10,42,47,48]$. In our study, $\mathrm{CO} 2$ was used in all interventions, which has contributed to the absence of symptoms in most patients, as it is easily and hastily absorbed. Yang et al. [40], based on CT findings after POEM, described similar incidences for air-associated complications while Wang et al. [33] detected insufflation-related complications in only $10.2 \%$ of the patients.

Concerning bleeding, some authors described rates of up to $17 \%[7,38]$, while in our study the incidence was $2.2 \%$. The rates for perforation and clip dislodgement were similar to other studies [7, 41].

Gastroesophageal reflux disease is the most frequent side effect of POEM, as well as of surgical myotomy, with similar reported prevalences [44]. The endoscopy allows the access to the muscular layer through the submucosal tunnel, leaving the surrounding structures intact $[5,30]$. Although when performing POEM the antireflux structures are preserved, GERD may still occur, which is why endoscopic fundoplication can be associated $[25,30]$.

In our study, given that our patients were still receiving PPIs at the 4-week follow-up, we could not quantify GERD using $\mathrm{pH}$-metry. However, no patient admitted to having heartburn, retrosternal pain or regurgitation, while endoscopic signs of esophagitis were encountered in only 10 cases. Based on symptoms, the incidence of GERD during the follow-up period was $16.17 \%$, but the symptomatology was controlled with standard PPI doses. Ali Khan et al. [46] and Khashab et al. [35] described similar rates, with an incidence between 14$16.7 \%$, while in other studies GERD was more frequent, with rates of around $40 \%[1,8,25,41]$.

For 17 patients, the primary treatment with POEM failed, but symptoms were subsequently relieved either by pneumatic dilatation or redoing the POEM. In one patient we performed a redo-POEM because the initial myotomy was incomplete and the patient presented a post-POEM Eckardt score identical to the one before intervention. Hoppo et al. [2] presented 
favorable results after a second intervention, but with a longer operative time $[6,22]$, a finding that we also noted, and which might be related to a more difficult esophageal dissection.

With a mean follow-up of 33.39 months, the therapeutic success $(87.5 \%)$ we achieved seems to remain steady, proving that POEM is a safe and effective long-term procedure. Our results are similar to other studies where symptom relief was noted in $82.4-91.3 \%$ of patients [24, 41, 47].

There was an increase in Eckardt score during follow-up (from 0.85 at one month to 1.07 for the last Eckardt score), but without statistical significance. Similar situations were reported by Teitelbaum et al. [48] and Filicori et al. [49], but statistical significance was reached in those studies. This increase could be attributed to a partial relapse of the disease. However, the recurrence could also be attributed to GERD, which presents some common symptoms to achalasia.

Few centers in the world have adopted POEM, our country being one of the few ones in Eastern Europe. Due to the frequency of the disease, as well as the complexity of achieving surgical-like performance, our center is the only one in Romania that published data about POEM. Data centralization in a single-center leads to a substantial decrease in the risk of analytical errors.

The number of technical errors and procedural duration tend to decrease after overcoming the learning curve [6]. Martinek et al. [8] did not show significant differences in effectiveness of therapy or duration of the procedure after overcoming this curve. Teitelbaum et al. [42] concluded that the duration of the procedure is not a standard of surgical skill for POEM while Liu et al. [43] described a reduction in interventional time after 70 cases.

\section{CONCLUSIONS}

POEM is a safe and effective minimally invasive therapeutic option which can substitute surgical myotomy, having a high success rate and a low rate of adverse events in short, medium and long-term.

Conflicts of interest: None to declare.

Authors' contribution: C.T. and M.T. conceived and designed the study. C.B. analyzed the data and drafted the manuscript. L.C.: revised the paper for scientific content. T.S.B. interpreted the manometry studies. A.T. analyzed the data and revised the paper. M.T. performed the POEMs and critically revised the manuscript.

Acknowledgements: The authors would like to thank Prof. Dr. Dan Dumitrașcu and Liliana David for scientific and technical support in the manometry studies. We also thank Claudia Buzas for her support in the patients' management.

\section{REFERENCES}

1. Esposito D, Maione F, D’Alessandro A, Sarnelli G, De Palma GD. Endoscopic treatment of esophageal achalasia. World J Gastrointest Endosc 2016;8:30-39. doi:10.4253/wjge.v8.i2.30
2. Hoppo T, Thakkar SJ, Schumacher LY, et al. A utility of peroral endoscopic myotomy (POEM) across the spectrum of esophageal motility disorders. Surg Endosc 2016;30:233-244. doi:10.1007/s00464015-4193-y

3. Haito-Chavez Y, Inoue H, Beard KW, et al. Comprehensive Analysis of Adverse Events Associated with per Oral Endoscopic Myotomy in 1826 Patients: An International Multicenter Study. Am J Gastroenterol 2017;112:1267-1276. doi:10.1038/ajg.2017.139

4. Wang J, Tan N, Xiao Y, et al. Safety and efficacy of the modified peroral endoscopic myotomy with shorter myotomy for achalasia patients: A prospective study. Dis Esophagus 2015;28:720-727. doi:10.1111/ dote. 12280

5. Patti MG, Andolfi C, Bowers SP, Soper NJ. POEM vs Laparoscopic Heller Myotomy and Fundoplication: Which Is Now the Gold Standard for Treatment of Achalasia? J Gastrointest Surg 2017;21:207-214. doi:10.1007/s11605-016-3310-0

6. Hungness ES, Sternbach JM, Teitelbaum EN, Kahrilas PJ, Pandolfino JE, Soper NJ. Per-oral endoscopic myotomy (POEM) after the learning curve: Durable long-term results with a low complication rate. Ann Surg 2016;264:508-515. doi:10.1097/ SLA.0000000000001870

7. Tantau M, Crisan D. Peroral endoscopic myotomy: Time to change our opinion regarding the treatment of achalasia? World J Gastrointest Endosc 2015;7:237-246. doi:10.4253/wjge.v7.i3.237

8. Martinek J, Svecova H, Vackova Z, et al. Per-oral endoscopic myotomy (POEM): mid-term efficacy and safety. Surg Endosc 2018;32:1293-1302. doi:10.1007/s00464-017-5807-3

9. Kurian AA, Dunst CM, Sharata A, Bhayani NH, Reavis KM, Swanström LL. Peroral endoscopic esophageal myotomy: Defining the learning curve. Gastrointest Endosc 2013;77:719-725. doi:10.1016/j. gie.2012.12.006

10. Demeter M, Ďuriček M, Vorčák M, Hyrdel R, Kunda R, Bánovčin P. S-POEM in treatment of achalasia and esophageal epiphrenic diverticula-single center experience. Scand J Gastroenterol 2020;55:509514. doi:10.1080/00365521.2020.1745881

11. Tantau M, Tantau A. Esophageal per oral endoscopic miotomy (POEM) for achalasia: First case reported in Eastern Europe. J Gastrointest Liver Dis 2013;22:461-463.

12. Tantau M, Buzas C, Tefas C, Groza A, Tantau A. "Learning curve" for the POEM procedure. J Gastrointestin Liver Dis 2015;24:536-537.

13. Stavropoulos SN, Modayil RJ, Friedel D, Savides T. The international per oral endoscopic myotomy survey (IPOEMS): A snapshot of the global POEM experience. Surg Endosc 2013;27:3322-3338. doi:10.1007/ s00464-013-2913-8

14. Uppal DS, Wang AY. Update on the endoscopic treatments for Achalasia. World J Gastroenterol 2016;22:8670-8683. doi:10.3748/wjg.v22. i39.8670

15. Arshava EV, Marchigiani RJ, Gerke H, et al. Per oral endoscopic myotomy: early experience and safety of a multispecialty approach Surg Endosc 2018;32:3357-3363. doi:10.1007/s00464-018-6056-9

16. Kumbhari V, Tieu AH, Onimaru M, et al. Peroral endoscopic myotomy (POEM) vs laparoscopic Heller myotomy (LHM) for the treatment of Type III achalasia in 75 patients: a multicenter comparative study. Endosc Int Open 2015;3:E195-E201. doi:10.1055/s-0034-1391668

17. Peng L, Tian S, Du C, Yuan Z, Guo M, Lu L. Outcome of Peroral Endoscopic Myotomy (POEM) for treating achalasia compared with Laparoscopic Heller Myotomy (LHM). Surg Laparosc Endosc Percutaneous Tech 2017;27:60-64. doi:10.1097/SLE.0000000000000368 
18. Ramirez M, Zubieta C, Ciotola F, et al. Per oral endoscopic myotomy vs. laparoscopic Heller myotomy, does gastric extension length matter? Surg Endosc 2018;32:282-288. doi:10.1007/s00464-017-5675-x

19. Talukdar R, Inoue H, Reddy DN. Efficacy of peroral endoscopic myotomy (POEM) in the treatment of achalasia: a systematic review and meta-analysis. Surg Endosc 2015;29:3030-3046. doi:10.1007/ s00464-014-4040-6

20. Wang X, Tan Y, Lv L, Zhu H, Chu Y, Li C, et al. Peroral endoscopic myotomy versus pneumatic dilation for achalasia in patients aged $\geq 65$ years. Rev Esp Enferm Dig 2016;108:637-641. doi:10.17235/ reed.2016.4488/2016

21. Parsa N, Khashab MA. POEM in the Treatment of Esophageal Disorders. Curr Treat Options Gastroenterol 2018;16:27-40. doi:10.1007/s11938018-0168-0

22. Nabi Z, Ramchandani M, Chavan R, et al. Peroral endoscopic myotomy in treatment-naive achalasia patients versus prior treatment failure cases. Endoscopy 2018;50:358-370. doi:10.1055/s-0043-121632

23. Fumagalli U, Rosati R, De Pascale S, et al. Repeated Surgical or Endoscopic Myotomy for Recurrent Dysphagia in Patients After Previous Myotomy for Achalasia. J Gastrointest Surg 2016;20:494-499. doi:10.1007/s11605-015-3031-9

24. Tyberg A, Seewald S, Sharaiha RZ, et al. A multicenter international registry of redo per-oral endoscopic myotomy (POEM) after failed POEM. Gastrointest Endosc 2017;85:1208-1211. doi:10.1016/j.gie.2016.10.015

25. Friedel D, Modayil R, Stavropoulos SN. Per-oral endoscopic myotomy: Major advance in achalasia treatment and in endoscopic surgery. World J Gastroenterol 2014;20:17746-17755. doi:10.3748/wjg.v20.i47.17746

26. Zhou PH, Li QL, Yao LQ, et al. Peroral endoscopic remyotomy for failed Heller myotomy: A prospective single-center study. Endoscopy 2013;45:161-166. doi:10.1055/s-0032-1326203

27. Jones EL, Meara MP, Pittman MR, Hazey JW, Perry KA. Prior treatment does not influence the performance or early outcome of per-oral endoscopic myotomy for achalasia. Surg Endosc 2016;30:1282-1286. doi:10.1007/s00464-015-4339-y

28. Orenstein SB, Raigani S, Wu YV, et al. Peroral endoscopic myotomy (POEM) leads to similar results in patients with and without prior endoscopic or surgical therapy. Surg Endosc 2015;29:1064-1070. doi:10.1007/s00464-014-3782-5

29. Estremera-Arévalo F, Albéniz E, Rullán M, Areste I, Iglesias R, Vila JJ. Efficacy of peroral endoscopic myotomy compared with other invasive treatment options for the different esophageal motor disorders. Rev Esp Enferm Dig 2017;109:578-586. doi:10.17235/reed.2017.4773/2016

30. Eleftheriadis N, Inoue H, Ikeda H, Onimaru M, Maselli R, Santi G Submucosal tunnel endoscopy: Peroral endoscopic myotomy and peroral endoscopic tumor resection. World J Gastrointest Endosc 2016;8:86-103. doi:10.4253/wjge.v8.i2.86

31. Duan T, Tan Y, Zhou J, Lv L, Liu D. A Retrospective Study of Peroral Endoscopic Full-Thickness Myotomy in Patients with Severe Achalasia. J Laparoendosc Adv Surg Tech A 2017;27:770-776. doi:10.1089/ lap.2016.0445

32. Cho YK, Kim SH. Current status of peroral endoscopic myotomy. Clin Endosc. 2018;51:13-18. doi:10.5946/ce.2017.165

33. Wang X, Tan Y, Zhang J, Liu D. Risk factors for gas-related complications of peroral endoscopic myotomy in achalasia. Neth J Med 2015;73:76-81.

34. Wang XH, Tan YY, Zhu HY, Li CJ, Liu DL. Full-thickness myotomy is associated with higher rate of postoperative gastroesophageal reflux disease. World J Gastroenterol 2016;22:9419-9426. doi:10.3748/wjg v22.i42.9419

35. Khashab MA, El Zein M, Kumbhari V, et al. Comprehensive analysis of efficacy and safety of peroral endoscopic myotomy performed by a gastroenterologist in the endoscopy unit: A single-center experience. Gastrointest Endosc 2016;83:117-125. doi:10.1016/j.gie.2015.06.013

36. Repici A, Fuccio L, Maselli R, et al. GERD after per-oral endoscopic myotomy as compared with Heller's myotomy with fundoplication: a systematic review with meta-analysis. Gastrointest Endosc 2018;87:934943.e18. doi:10.1016/j.gie.2017.10.022

37. Shiwaku $\mathrm{H}$, Inoue $\mathrm{H}$, Sasaki $\mathrm{T}$, et al. A prospective analysis of GERD after POEM on anterior myotomy. Surg Endosc 2016;30:2496-2504. doi:10.1007/s00464-015-4507-0

38. Misra L, Fukami N, Nikolic K, Trentman TL. Peroral endoscopic myotomy: Procedural complications and pain management for the perioperative clinician. Med Devices (Auckl) 2017;10:53-59. doi:10.2147/MDER.S115632

39. Crespin OM, Liu LWC, Parmar A, et al. Safety and efficacy of POEM for treatment of achalasia: a systematic review of the literature. Surg Endosc 2017;31:2187-2201. doi:10.1007/s00464-016-5217-y

40. Yang S, Zeng MS, Zhang ZY, Zhang HL, Liang L, Zhang XW. Pneumomediastinum and pneumoperitoneum on computed tomography after peroral endoscopic myotomy (POEM): Postoperative changes or complications? Acta Radiol 2015;56:1216-1221. doi:10.1177/0284185114551399

41. Von Renteln D, Fuchs KH, Fockens P, et al. Peroral endoscopic myotomy for the treatment of achalasia: An international prospective multicenter study. Gastroenterology 2013;145:309-311.e3. doi:10.1053/j.gastro.2013.04.057

42. Teitelbaum EN, Soper NJ, Arafat FO, et al. Analysis of a Learning Curve and Predictors of Intraoperative Difficulty for Peroral Esophagea Myotomy (POEM). J Gastrointest Surg 2014;18:92-99. doi:10.1007/ s11605-013-2332-0

43. Liu Z, Zhang X, Zhang W, et al. Comprehensive Evaluation of the Learning Curve for Peroral Endoscopic Myotomy. Clin Gastroenterol Hepatol 2018;16:1420-1426.e2. doi:10.1016/j.cgh.2017.11.048

44. Wei M, Yang T, Yang X, Wang Z, Zhou Z. Peroral esophageal myotomy versus laparoscopic Heller's myotomy for achalasia: A meta-analysis. J Laparoendosc Adv Surg Tech A 2015;25:123-129. doi:10.1089/ lap.2014.0454

45. Inoue $\mathrm{H}$, Ueno $\mathrm{A}$, Shimamura $\mathrm{Y}$, et al. Peroral endoscopic myotomy and fundoplication: A novel NOTES procedure. Endoscopy 2019;51:161164. doi:10.1055/a-0820-2731

46. Khan MA, Kumbhari V, Ngamruengphong S, et al. Is POEM the Answer for Management of Spastic Esophageal Disorders? A Systematic Review and Meta-Analysis. Dig Dis Sci 2017;62:35-44. doi:10.1007/s10620016-4373-1

47. He C, Li M, Lu B, et al. Long-Term Efficacy of Peroral Endoscopic Myotomy for Patients with Achalasia: Outcomes with a Median Follow-Up of 36 Months. Dig Dis Sci 2019;64:803-810. doi:10.1007/ s10620-018-5373-0

48. Teitelbaum EN, Dunst CM, Reavis KM, et al. Clinical outcomes five years after POEM for treatment of primary esophageal motility disorders. Surg Endosc 2018;32:421-427. doi:10.1007/s00464-017-5699-2

49. Filicori F, Dunst CM, Sharata A, et al. Long-term outcomes following POEM for non-achalasia motility disorders of the esophagus. Surg Endosc 2019;33:1632-1639. doi:10.1007/s00464-018-6438-Z 